\title{
PARTICIPATORY RURAL APPRAISAL IMPLEMENTATION IN IDENTIFYING PUBLIC OPEN SPACE
}

\author{
Trias Megayanti ${ }^{1}$, Dian Fitria ${ }^{2}$ \\ 1,2 Architecture, Universitas Pendidikan Indonesia, Bandung, Indonesia \\ corresponding author: trias@upi.edu \\ dianfitria692@gmail.com
}

Received: 4 April 2020
Revised: 15 April 2020
Article History:

Accepted: 20 Apri;

2020
Available online: 30 April 2020

\begin{abstract}
Public open space performs an important role to enhance the quality of community living as well as being beneficial in maintaining the ecosystem. It is also having a prominent role in disaster risk management applied to densely populated settlements. Nevertheless, social awareness about the essential role and the use of green open space is still a concern. The aim of this paper is to present the results of the identification of potential public open spaces conducted by residents in densely populated urban villages. This study is conducted by the Participatory Rural Appraisal (PRA) methods, which was carried out in collaboration with the local community group, to asses the potency of green open space at Nagrikaler, Purwakarta Regency, Indonesia. The result shows that community empowerment in optimizing public space, requires a critical awareness process for the local community to maintain environmental sustainability and social interaction. It is also shows the mapping of green open space at the village. The results from this study is being used as guidelines for designing green open spaces with community architecture methods based on the needs of the local community.
\end{abstract}

Keywords - community architecture, participatory, PRA, public space,

\section{Introduction}

Public open space performs an essential role to enhance the quality of community living as well as being beneficial in maintaining the ecosystem. Predominantly, public space has various functions (Carr, Francis, Rivlin, \& Store, 1992) including as a space to improve visual and environmental quality, economic development and community welfare, and create a certain impression that will be embedded in people's memories. Indirectly, well-designed public open spaces will also increase economic value and environmental quality (Williams, Green, \& Mcglynn, 2001). Public open spaces that function as green spaces also have important role in maintaining ecosystem functions (Daniels et al., 2018). Furthermore, it is said that green space can be economic, social and environmental benefits. From a social perspective, the existence of a well-designed public space can accommodate social activities that will strengthen social ties between citizens and between citizens and their environment. Public space also has benefits and advantages in improving the economy, bringing benefits to human health, a means of socializing, protecting the environment (Carmona, Heath, Oc, \& Tiesdell, 2017).

Nevertheless, social awareness about the essential role and the use of green open space is still a concern. Open space in urban areas has diminished with increasing population growth. With the increase in population, the increasing space needs for settlements. The need for residential space forces people to optimize the space they have. As a result, there is misuse of spatial planning, increasing slum areas, and increasingly narrowing and even reduced open space. Thus, open space in residential areas must be utilized according to its role as a space for citizen interaction However, the role of citizens is equally significant in an effort to restore the function of open space. Citizens' awareness is the key to the sustainability of open space functions that can run well in the residential area. 
Purwakarta is one of the regency in West Java, Indonesia, which has an area of $971.72 \mathrm{Km} 2$. Administratively, Purwakarta has 17 sub-districts and 192 villages. Nagrikaler is the capital of subdistrict of Purwakarta, which has the highest population density, reaching $35 \%$, amounting to 174,740 of the total population of Purwakarta Regency totaling 950,070 residents. Nagrikaler is also the most populous region in Purwakarta Regency, which is 7037.45 per square kilometer (BPS, 2018). As the Capital of subdistrict of Purwakarta, Nagrikaler has some issues regarding to public open space. Significant population growth and the absence of careful planning make settlements become dense and open space is lost. Occupancy of green spaces and river banks is common, due to the increased space requirements.

The aim of this paper is to identify areas that are used by citizens as communal space, as well as identification of open spaces that have the potential to become communal spaces by using the Participatory Rural Appraisal (PRA) approach. This article will deliberate the method of participatory mapping, which is the initial stage in designing together with the community through the PRA approach. The term PRA is an approach that allows local people to partake, and analyze their understanding of conditions and their lives, to plan and to act (Chambers, 1994b). The approach taken is facilitating citizens with an emphasis on empowerment and equality as well as with the purpose of changing views, behavior, and learning is done by the community itself. The principles used in the PRA approach include (Chambers, 1994b): the people who have to do it themselves, the facilitator continuously conducts self reflection, personal responsibility, and sharing. The PRA approach is carried out using several techniques such as participatory maps, semi structural interviews, field walks, which must be triangulated using other techniques (Chambers, 1994a).

The PRA approach is used to increase the sense of community as well as a sense of place between citizens and their environment. Through a series of processes in the PRA approach, residents are invited to identify themselves and the environment along with the problems faced. Residents are also invited to identify potential and make plans and actions that they can do themselves to solve the problem. The basis for implementing the PRA method is in addition to increase the active participation of the community. Active community participation is very important because the people who recognize the problems they face the most, and that are not less important they are experienced to analyze and explore solutions to the problems they face. Building social capital is the primary role in decision making and believes they "own" the process as they move away from being dependent (Sanoff, 2000).

\section{Method}

This study was conducted by the PRA methods, which was carried out in collaboration with the local community group, to asses the potency of public open space at Kampoong Nagrikaler, Purwakarta Regency, Indonesia. The principles of participatory implementation generally prioritize efficiency, sustainability, equity, and improve decision making by the community (FAO, 2009). Hence, the stages and methods of its implementation are very dependent on the social conditions of the local community. The PRA approach in this study was carried out through 5 stages i.e. Stage 1 preparation, Stage 2 identification of open spaces and problems, Stage 3 Design ideas development, stage 4 ranking, stage 5 monitoring and evaluation. Data collection was conducted using the method of field walk, participatory mapping, and Focus Group Discussion (FGD). Groups of people who are involved are volunteers comprised of representatives of residents and community leaders as many as twelve people. The study was conducted in Hamlet/RT 10 and neighborhood/RW 10 of Nagrikaler Purwakarta Village every weekend within 3 months. The location can bee seen in Figure 1. 


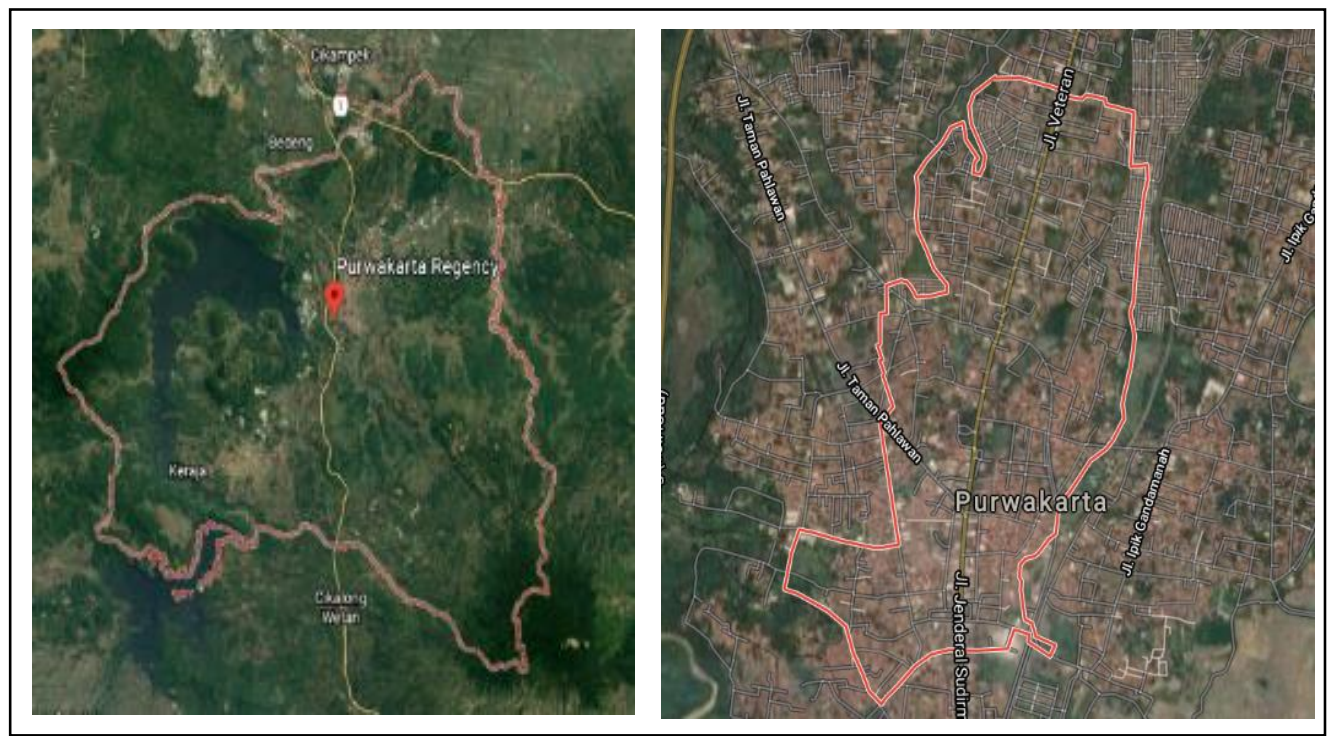

Figure 1: Study location: Purwakarta Regency (left), Nagrikaler Village (right), 2020. Source: processed from Google earth

\section{Results and Discussion}

The identification of open spaces in the Nagrikaler Purwakarta Village runs according to the plan within three months and is held every weekend following the availability of community time. In accordance with the research plan, the five stages have been carried out can bee seen in figure 2 .

a. Preparation

This stage is the initial stage of the series of activities. The method used at this stage is community meeting. This phase begins with socialization carried out on community representatives. The results of this preparatory phase are agreements regarding the willingness of citizens to participate in activities, time of implementation, and how many people can participate in the process. Ideally, PRA activities can be followed by as many citizen representatives as possible. However, time constraints an obstacle so that it can not be implemented.

b. Identification

There are two things identified according to the purpose of this study, comprise identification of space that has been used as communal space, and identification of open spaces that offer the potential to be used as public open air and communal spaces for citizens. To achieve this goal, this stage is carried out with two methods, comprise the field walk and Participatory mapping.

Field walk is the method where participants are invited to take a walk around their village area, especially in RT 10 or just keep quiet in a location while observing the environment. In practice, participants were invited to record all formal and non-formal elements found in their neighborhood. They were also asked to recall, what happened to the open space and what changes had occurred. They also showed the group about the spaces used for community space. In addition to matters related to the physical environment, they also then see and discover social problems which have often not visible due to the busyness of each participant. In addition to matters related to the physical environment, they also then see and discover social problems which have often not visible due to the busyness of each participant. At this stage, they are asked to take notes and draw informal sketches.

Participatory mapping represent a detailed process in the form of clearer sketches. This stage is carried out indoors by all groups after the field walk is complete. Data in the form of notes and rough sketches from each group will be collected and redrawn while deliberated. At this stage, mapping of the potential and opportunities of each open space visited in the field walk was also carried out. Another thing to achieve is to identify the types of activities carried out when residents gather. Image maps are made by residents will be redrawn by experts that are technically better readability.

c. Ideas development

This stage invites all participants to imagine the possibilities that will occur in the future. As it is known, that changes will always come and cannot be prevented. However, people are invited 
to realize they can face and manage the impact that will occur, especially negative impacts. At this stage, each group is asked to describe their expectations about the ideal public open space and accommodate their needs. The participants in the group were released to include all ideas that were related to the possible function of open space, the types of trees to be planted, the form of design to the required open space furniture and others related.

d. Ranking

At this stage participants are invited to make an action plan related to the design of public open spaces in their environment. The results of this stage are identification of priorities related to open space and user groups of users. All user needs, potential and possible problems are discussed together. The next step they determine the open space that is a priority to be developed and make plans for how to realize the design of public open spaces related to the resources needed.

e. Evaluation

At this stage participants are invited to re-evaluate the things that have been done. They were also asked to express their opinions regarding the experience of the PRA method implemented. The results of the study showed that there was enthusiasm from the participants in following the whole process. However, time constraints are an obstacle in this process. Participants hope the study area is not only in one hamlet (RT) but one village so that alternative solutions can be analyzed comprehensively. At this stage participants were also asked to make an action plan in tackling environmental problems by relying on existing resources

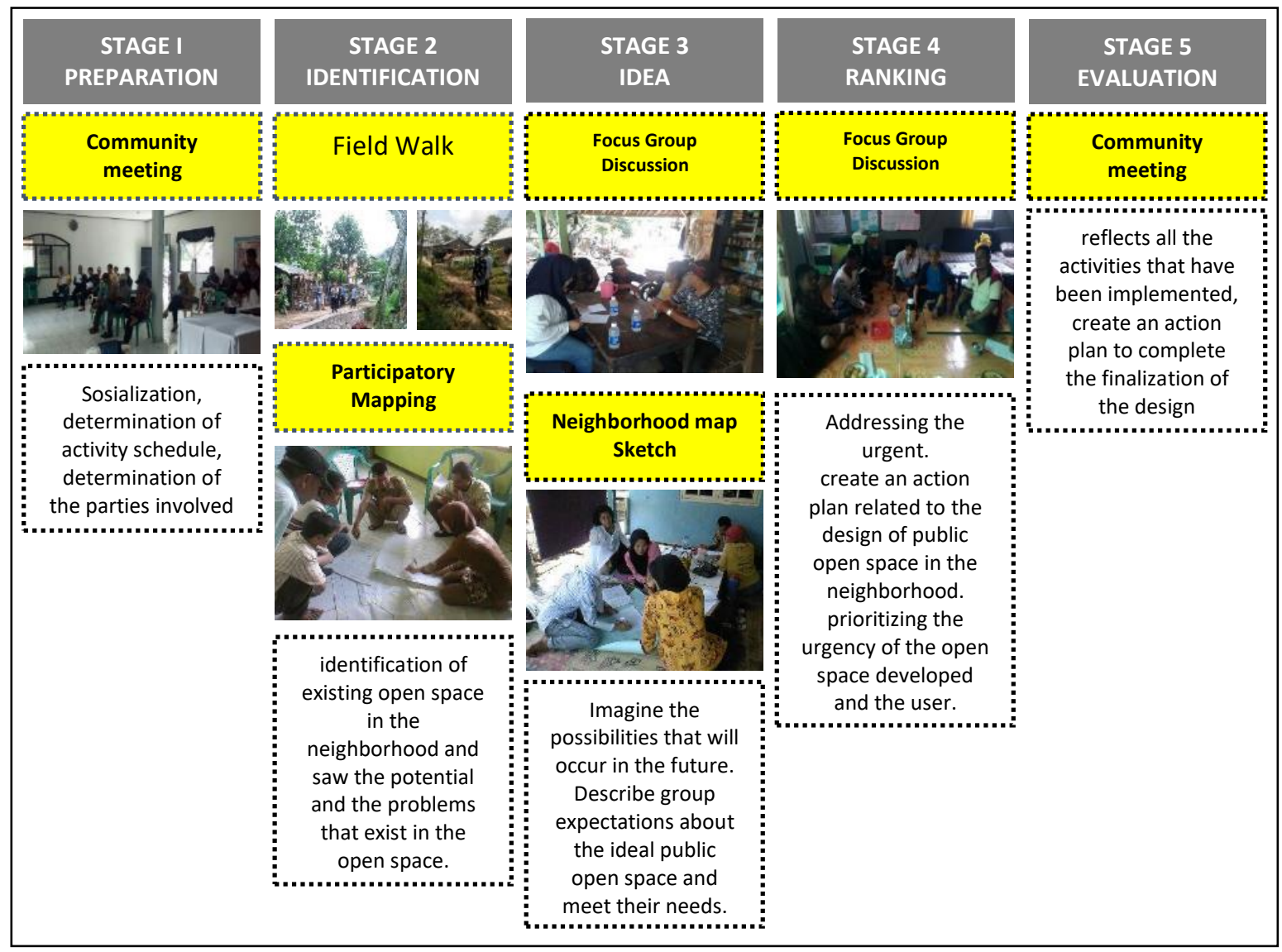

Figure 2: The implementation of PRA Approaches, 2019, Source: Study documentation

The results show that RW 10 of the Nagrikaler Subdistrict consists more of a dense area. Open space that has the potential to be used as communal space is still very limited, especially due to the absence of public land. The vacant land is identified as belonging to the residents so that even though it is permitted to be used as communal space for residents, the nature is only temporary. Hence, residents often gather on roadside, community stalls, or on vacant land owned by residents. The study results show that in the study area there is no public space open space. However, 
residents have open spaces in the form of government-owned fields used for certain events and located outside the study area. When referring to the definition of public open space, namely open space which is a forum for functional activities and ritual activities that bring together a group of people in the normal routine of daily life and in periodic activities (Carr et al., 1992), the need for public space in the study area has been fulfilled although not ideal. With limited vacant land, residents want to optimize the greening on the yard. Specifically, residents also want the use of productive plants as greening the area of their home environment. For the time being in the study area, no vacant land was found that has the potential to be developed and designed to be a public open space.

Involving the community to identify potentials and problems in the surrounding environment is certainly not easy. Residents mostly reluctant, especially these activities took a lot of their time, as well as the direct benefits perceived to be minimal. In this approach, the residents can not be forced to follow the entire process sequence, hence the approach to the citizens need to be implemented carefully, so that residents voluntarily participate in this event. An approach that emphasizes community participation needs to prioritize togetherness, willingness, and social responsibility of the community members themselves (Cilliers, Timmermans, Goorbergh, \& Slijkhuis, 2017). In this study, licensing from village head is key to ensure the success of this study, due to the citizens of Purwakarta that are highly respect the direction and input from the village head and other village officials such as head of neighbourhood and hamlet. The approach was carried out by providing understanding and socialization for village officials first, then continue the stage of sosialization through out all off the citizen of the hamlet. Dissemination becomes an important step regarding the purpose of the activity, and how important the community's involvement is in carrying out the process. Once they understand, some volunteers from among mothers and young people willing to participate in this event.

The process of identifying the potential and environmental problems undertaken by the participants, indirectly fostered a sense of community among the residents. In the process, participants see more clearly about the surrounding environmental and social issues. The process also fosters a sense of shared ownership and responsibility in maintaining open space. The environment, especially open space, can strengthen the social relations of the surrounding community and can also increase the sense of ownership of open space (Strydom \& Puren, 2013). This process also opened the minds of the participants in particular, that the problems and limitations they had with regard to the availability of public open spaces and green spaces, could be dealt with with their own potential. Optimizing home yards, and improving environmental infrastructure were agreed by participants as a start to improve the problem of limited public open space. Increasing community participation in recognizing the environment can increase the creativity of citizens in finding solutions to the problems they face. Through the method of participation, people can better understand their individual roles can be very important for the environment. The process of structuring open space involving citizens is expected to increase positive interactions and strengthen social ties between citizens. Furthermore, a well-organized and functioning public open space is expected to be able to better attach social capital among the surrounding residents. Public space has a social value that depends on the contribution and involvement of users (Worpole \& Knox, 2007).

Through PRA, citizens who follow this process realize the importance of the role of open space on social aspects as a tool to strengthen the community. They also realized green space was needed especially in densely populated settlements. Green areas can be realized through optimizing existing spaces such as planting productive plants and implementing vertical gardens on the home yard. Furthermore, the involvement of the community can foster social capital as a leading role in the process of community empowerment (Sanoff, 2000). This can be seen from the process of critical awareness of the participants about the importance of their role as community members in solving problems that occur in their environment.

While the positive results have been described previously, the use of the PRA method in this case also faces various obstacles. The amount of time needed in a gradual process, makes not all participants consistently follow each stage. Noted, several participants missed one stage. Another obstacle is that participation is voluntary, so participants have not represented all groups. The activity was only attended by residents who were accustomed to being active in organizational activities at the village level. Decisions made by participant groups will not necessarily represent the needs of the general public regarding the use of public space. Another obstacle is the limited time and cost, causing the activity to only be carried out in one hamlet so identification is partial and has not been able to solve the problem as a whole. Strengths in activities that involve community participation 
include increased understanding and skills for participants, while the lack of use of community participation methods is the use of time and money and the possibility of decision making that does not represent the wider community (Irvin \& Stansbury, 2004). Although involving the community is not an easy activity, this method is able to facilitate the community to better understand the goals, identify problems and develop problem solving strategies (Muller \& Kuhn, 1993).

\section{Conclusion}

The implementation of the PRA method to optimize open space in the community is quite difficult to implement. However, in this case, the key to success in activities lies in the approach to the community through socialization that begins with key community leaders. Active community participation can be carried out because of the understanding and the desire of citizens to get involved. The process of understanding and critical awareness of the community is the next step in efforts to optimize public open space. Often, people are not aware of problems in their environment. Furthermore, the community is also unaware that they have the potential to be part of the solution to the problem. PRA helps facilitate the process of aligning perceptions and goals, identifying problems and prioritizing the best problem solving strategies for all citizens. Apart from the drawbacks of community participation methods, fostering active community participation is proven to be able to increase awareness of the surrounding environmental and social problems.

Through the PRA method, the primary goal is not only to design the environment, but also the process of community awareness about the potential they have in exploring information, data needs, and recognizing problems and finding solutions to these problems. The steps for withdrawing in this article are the representations of the series of design processes involving the community.

The identification results in the form of open space mapping along with potential problems will then become a material study to complete the design details. Time limitations caused the community groups are involved and the study area to be limited. In the subsequent studies, analysis of forms of community participation needs to be taken into account at the level of individual participation. Analyzing the levels of stakeholders that need to be involved is also important in the planning stage before the activity starts.

\section{References}

BPS. (2018). Kabupaten Purwakarta dalam Angka 2018.

Carmona, M., Heath, T., Oc, T., \& Tiesdell, S. (2017). The Dimensions of Urban Design. In Gggg.

Carr, S., Francis, M., Rivlin, L. G., \& Store, A. M. (1992). Public Space. Australia: Press Syndicate of University of Cambridge.

Chambers, R. (1994a). Participatory rural appraisal (PRA): Analysis of experience. World Development, 22(9), 1253-1268. https://doi.org/10.1016/0305-750X(94)90003-5

Chambers, R. (1994b). Participatory rural appraisal (PRA): Challenges, potentials and paradigm. World Development, 22(10), 1437-1454. https://doi.org/10.1016/0305-750X(94)90030-2

Cilliers, E. J., Timmermans, W., Goorbergh, F., \& Slijkhuis, J. S. A. (2017). Designing public spaces through the lively planning integrative perspective. Environment, Development and Sustainability, (December 2015). https://doi.org/10.1007/s10668-014-9610-1

Daniels, B., Zaunbrecher, B. S., Paas, B., Ottermanns, R., Zie, M., \& Roß-nickoll, M. (2018). Science of the Total Environment Assessment of urban green space structures and their quality from a multidimensional perspective. 615, 1364-1378. https://doi.org/10.1016/j.scitotenv.2017.09.167

FAO. (2009). Mapping our community's future: why and how to practice participatory land-use planning. Sustaining Communities, Livestock and Wildlife - a Guide to Participatory Land-Use Planning, $26-47$. Retrieved from ftp://ftp.fao.org/docrep/fao/011/i0821e/i0821e.pdf

Irvin, R. A., \& Stansbury, J. (2004). Citizen Participation in Decision Making: Is It Worth the effort? Public Administration Review, 64(1), 55-65. https://doi.org/10.1111/j.1540-6210.2004.00346.x

Muller, M. J., \& Kuhn, S. (1993). Participatory design. Communications of the ACM, 36(6), $24-28$. https://doi.org/10.1145/153571.255960

Sanoff, H. (2000). Community Participation Methods in Design and Planning. Landscape and Urban Planning, 50(4), 270-271. https://doi.org/10.1016/s0169-2046(00)00063-3

Strydom, W., \& Puren, K. (2013). A participatory approach to public space design as informative for placemaking. Challenges of Modern Technology, 4(4), 33-40.

Williams, K., Green, S., \& Mcglynn, S. (2001). Literature Review of Public Space and Local Environments for the Cross Cutting Review FINAL REPORT Prepared for. (November).

Worpole, K., \& Knox, K. (2007). The social value of public spaces. Joseph Roundtree Foundation. https://doi.org/10.1016/j.jse.2005.03.007 